\title{
O DIAMANTE NA BACIA DO RIO SANTA ROSA, TIBAGI (PR)
}

\section{LEILA C. PERDONCINI* \& PAULOC. SOARES**}

\begin{abstract}
THE DIAMOND OF THE SANTA ROSA RIVER BASIN, TIBAGI (PR) Several diamond occurences exist in the northern, northwestern and southeastern flanks of the Paraná Basin. In the southeast, the Tibagi river valley has yielded important gem quality diamonds which had been investigated by means of mineralogical characterization, detailed mapping and sedimentological studies in the Tibagi basin in general and in the Santa Rosa river in particular. Diamond surface textures and the lack of kimberlitic indicator minerais in the digging areas investigated indicate that the diamonds are unlikely to have been derived from a local primary source. Diamond morphology and mosphoscopic surface textures are not fully consistent with the nature of the recent sediments from which the diamonds have been recovered and part of the mineralogical assemblage in the digging areas have been inherited from one or more pre-existing secondary sources. Selected facies in the Itararé Group is inferred to have been one of such pre-existing secondary source, based on of texture and mineralogy and depositional process. Notwithstanding the poor concentration capacity of glacial environments, it is suggested that fluvial rework during the deposition of the lower Itarare Group led to the formation of reverse graded channels and re-sedimentation processes which had the diamonds incorporated in such glaciogenic deposits could have been derived from the Kaapvaal craton in South África and transported by the Kaokoveld glacial plume.

Keywords: Diamonds, Itararé Group, Paraná Basin.
\end{abstract}

RESUMO São bastante conhecidas as diversas ocorrências de aluviões diamantíferos na Bacia do Paraná, destacando-se as da bacia do Rio Tibagi, no Estado do Paraná. As bacias de drenagem diamantíferas estão localizadas sobre rochas sedimentares de idade ordoviciana a permiana, predominando amplamente a ocorrência em domínios de litologias do Grupo Itararé. As pesquisas e trabalhos de prospecção na área tem sido orientadas no sentido de buscar a fonte primária em rochas kimberlíticas. Entretanto diversos autores já tem manifestado a possibilidade de que a fonte dos diamantes seja formada pelas rochas sedimentares carbonifero-permianas (Grupo Itararé) ou devonianas (Formação Furnas). Este trabalho relata os resultados de uma investigação realizada na bacia do rio Santa Rosa, uma das bacias diamantíferas mais conhecidas e circunscritas a rochas do Grupo Itararé (C) e da Formação Ponta Grossa (D). Foram identificadas, definidas e mapeadas as diferentes fácies da porção basal do Grupo Itararé, especialmente aquelas com maior favorabilidade para constituírem a rocha fonte, tanto pelas características faciológicas como mineralógicas e genéticas. Os resultados indicam que as fácies conglomeráticas trativas e parcialmente as ressedimentadas basais do referido grupo constituem as fácies preferenciais para constituírem a fonte dos aluviões diamantíferos.

Palavras-chaves: Diamantes, Grupo Itararé, Bacia do Paraná.

INTRODUÇÃO Nos flancos leste e norte-noroeste da Bacia do Paraná são conhecidas diversas ocorrências quaternárias de diamantes associadas espacialmente às sequências basais Ordovício-silurianas (Grupo Rio Ivaí) e Devoniana (Formação Furnas) e Pensilvaniana-Permiana (Grupo Itararé) (Fig. 1), sendo que no Estado do Paraná (Fig. 2) a principal região mineralizada a diamante na forma de pláceres é a do rio Tibagi, com alguns de seus afluentes também mineralizados. Um desses afluentes, o rio Santa Rosa, nasce e desenvolve-se quase que exclusivamente sobre rochas do Grupo Itararé e, antes de desaguar no rio Tibagi, corta os sedimentos da Formação Ponta Grossa.

Diversos autores relacionam geneticamente as mineralizações de diamantes da região do rio Tibagi, Paraná, tendo sido atribuídas a kimberlitos, quanto à glaciação permo-carbonífera. Até o presente, todavia, não foram desenvolvidas pesquisas detalhadas que permitissem verificar a influência da atividade glacial nas mineralizações, nem os processos que teriam promovido a formação dos pláceres quaternários.

A capacidade de erosão e o volume de sedimentos transportados por geleiras são altos, contudo, para que ocorra mineralização é necessária a atuação de processos deposicionais seletivos que promovam a concentração do material transportado, por meio de: i) existência de uma pré-concentração de minerais durante o transporte glacial; ii) atuação de processos trativos durante a sedimentação (observado somente nos depósitos de outwash e eskers); iii) retrabaIhamento dos depósitos glaciais por processos trativos.

A existência de diamantes em aluviões atuais em uma microbacia de drenagem com fonte circunscrita a rochas do Grupo Itararé poderia estar relacionada a conglomerados trativos derivados de fácies glaciais. Se este fosse o caso, as fácies, a assembleia mineralógica e as feições morfoscópicas deveriam revelar esta origem sedimentar.

Relatamos aqui o estudo da distribuição das mineralizações diamantíferas, das características das fácies sedimentares e mineralógicas, demonstrando a coerência de suas propriedades com o que se esperaria ser uma rocha fonte para os sedimentos recentes diamantíferos desta bacia.

A literatura sugere uma associação genética dos diamantes com os sedimentos glaciogênicos do Grupo Itararé, com base principalmente na sua distribuição geográfica, no fato das pedras serem de qualidade gema e na ausência de minerais satélites de fontes primárias. Outra hipótese diz respeito a presença de fontes kimberlíticas diamantíferas na área de estudo, relacionadas ao Arco de Ponta Grossa ou ao embasamento pré-cambriano (Reis \& Cunha Neto 1982).

Neste trabalho é apresentado o tipo de associação entre a mineralização e as rochas sedimentares glaciogênicas do Grupo Itararé com base em: i) distribuição das fácies preferenciais para ocorrência de depósitos detríticos; ii) características da assembleia de minerais pesados tanto dos aluviões e paleoaluviões da microbacia mineralizada do rio Santa Rosa, como dos sedimentos permo-carboníferos adjacentes; iii) tipologia das formas e das feições morfoscópicas dos diamantes. Estas características foram utilizadas como indicadores ou critérios diag-nósticos da relação entre a fonte do diamante e as rochas permocarboníferas.

DEPÓSITOS DIAMANTÍFEROS NO ESTADO DO PARANÁ Distribuição e tipos de ocorrências As ocorrências de diamantes, descritas no Estado do Paraná, apresentam-se em três tipos distintos de depósitos, os quais incluem: i) cascalhos de leito ativo dos rios, ii) os de meandros abandonados ("barrancos") e páleocanais na planície de inundação, iii) os de terraços aluvionares e rampas coluvionares antigas ("monchões ou manchas isoladas") (Chieregati et al. 1984, Chieregati 1989, Cruz 1985, e Oppenheim 1936). Estes últimos contêm pláceres antigos, constituídos de coluviões e aluviões, em cotas superiores às dos rios atuais.

Além dessas formas de ocorrências, Oppenheim (1936) e Chieregati (1989) descrevem a ocorrência de cascalhos diamantíferos na região de Lageado Bonito e no Garimpo do Marcola (a NW de Telêmaco Borba) como, respectivamente, derivados de desagregação in situ ou por transporte aquoso de sedimentos do Grupo Itararé, enquanto Maack (1968) refere-se à extração de diamantes nos sedimentos glaciogênicos.

A maior concentração das ocorrências diamantíferas do vale do rio Tibagi, tanto em pláceres quanto em sedimentos de leito ativo, localizase no trecho compreendido entre a desembocadura do rio Pitangui (também diamantífero, segundo Derby 1878) e a localidade de Salto Mauá, onde predominam sedimentos glaciogênicos do Grupo Itararé.

Mais raramente, são também conhecidas ocorrências diamantíferas em depósitos e sedimentos de leito ativo de rios que drenam as rochas das formações Furnas, Ponta Grossa, Rio Bonito e Palermo, embora nestes casos algum trecho de seu curso ou de seus afluentes estejam erodindo rochas do Grupo Itararé. A maioria dos rios mineralizados nasce e desenvolve-se exclusivamente sobre os sedimentos paleozóicos, estando, muitas vezes, encaixados integralmente em áreas de afloramentos dos sedimentos permo-carboníferos. Mesmos nos pláceres posicionados sobre rochas da Formação Furnas é comum, de acordo com Chieregati (1989), a presença de material rudáceo proveniente do Grupo Itararé. Além disso, minerais acompanhantes do diamante e que participam também da assembleia mineralógica dos sedimentos glaciogênicos permo-carboníferos (hematita, turmalina preta e jaspilito) não são identificados na Formação Furnas.

A associação das mineralizações aos diques básicos, que interceptam o curso natural de algumas drenagens, está relacionada à formação de armadilhas "tipo travessão" (Weska 1996) geradas por represamento das águas à montante ou panelas formadas por turbilhonamento à jusante.

Pós-Graduação (Doutorado) - DPM - UNESP. Av. 24A/1515. CEP 13506-900, Rio Claro/SP, e-mail: leilacp@caviar.igce.unesp.br

Departamento de Geologia - UFPR. Centro Politécnico. CEP 81531-990, Curitiba/PR. 


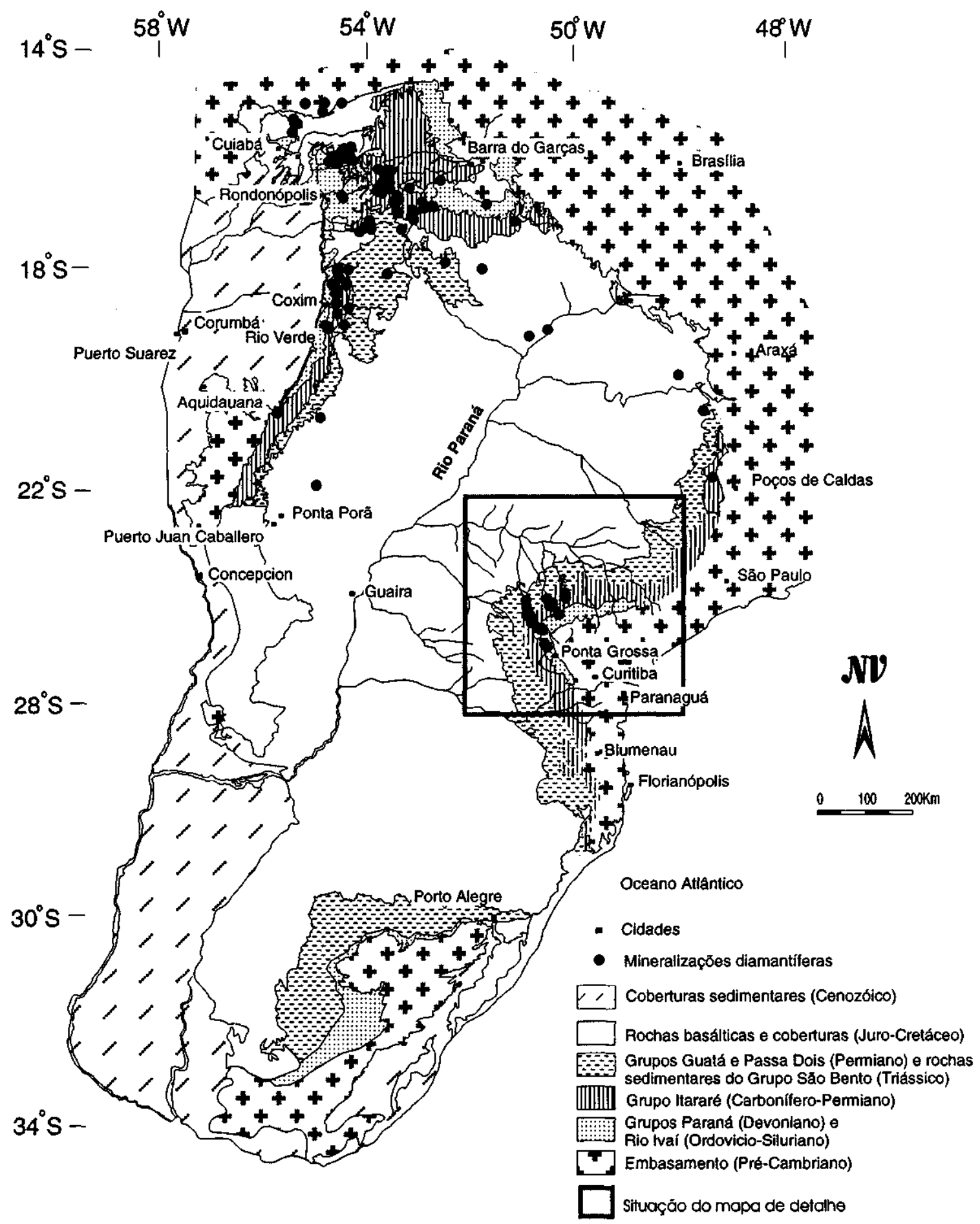

Figura l- Distribuição das ocorrências quaternárias de diamante espacialmente associadas às unidades paleozóicas da Bacia do Paraná. (Mapa base modif. de Soares et al. 1995).

O ouro está associado a maioria dessas ocorrências de diamante, fato que, segundo Perdoncini et al. 1995, sugere que a formação dos depósitos aluviais e paleoaluviais é devido a atuação repetitiva de ciclos glaciais, alternados por transporte fluvial, permitindo a concentração associada de minerais de fontes primárias diferentes. Características dos diamantes Segundo Chieregati (1989), nas regiões de Itararé-Jaguariaíva e Telêmaco Borba-Tibagi, cerca de $60 \%$ das pedras são rombodo-decaédricas, $16,5 \%$ são de hábito transicional rombododecaedro-octaedro, $8 \%$ a $3 \%$ são octaédricas enquanto que os fragmentos apresentam-se em tomo de $12 \%$ e $5 \%$ e os restantes diferenciam-se em geminados, irregulares, Baila e agregados. Com relação a cor das pedras de diamantes, $50 \%$ a $60 \%$ são incolores, ocorrendo de $30 \%$ a $21,5 \%$ castanho claras, $13 \%$ a $8,5 \%$ castanho escuras, $12 \%$ a $3 \%$ amarelas e $1 \%$ a $4 \%$ verdes.
Oppenheim (1936) descreve cristais de tamanho em geral pequeno, da ordem de um quilate ou menos, e eventuais pedras de 15 a 35 ct, mencionando a descoberta de um diamante de 150 ct e um carbonado de 105 ct. Segundo Chieregati (1989), as gemas apresentam-se em média com tamanho pequeno, em tomo de 0,10 ct, ocorrendo também pedras de cerca de 0,30 ct e, raramente, de 9,0 ct. Contudo, não existe um monitoramento da variação do tamanho médio desses diamantes com relação ao transporte.

Olivina, enstatita, granada, piroxênio, cromoespinélio, pirrotita e diamante foram identificados por Svisero (1979) como inclusões singenéticas em $20 \%$ das pedras. Baseado na composição química das inclusões, este autor as caracteriza como de natureza peridotítica e considera os diamantes do Tibagi semelhantes aos da África e da Sibéria. Harris \& Gurney (1979, apud Chieregati et al. 1984) citam 

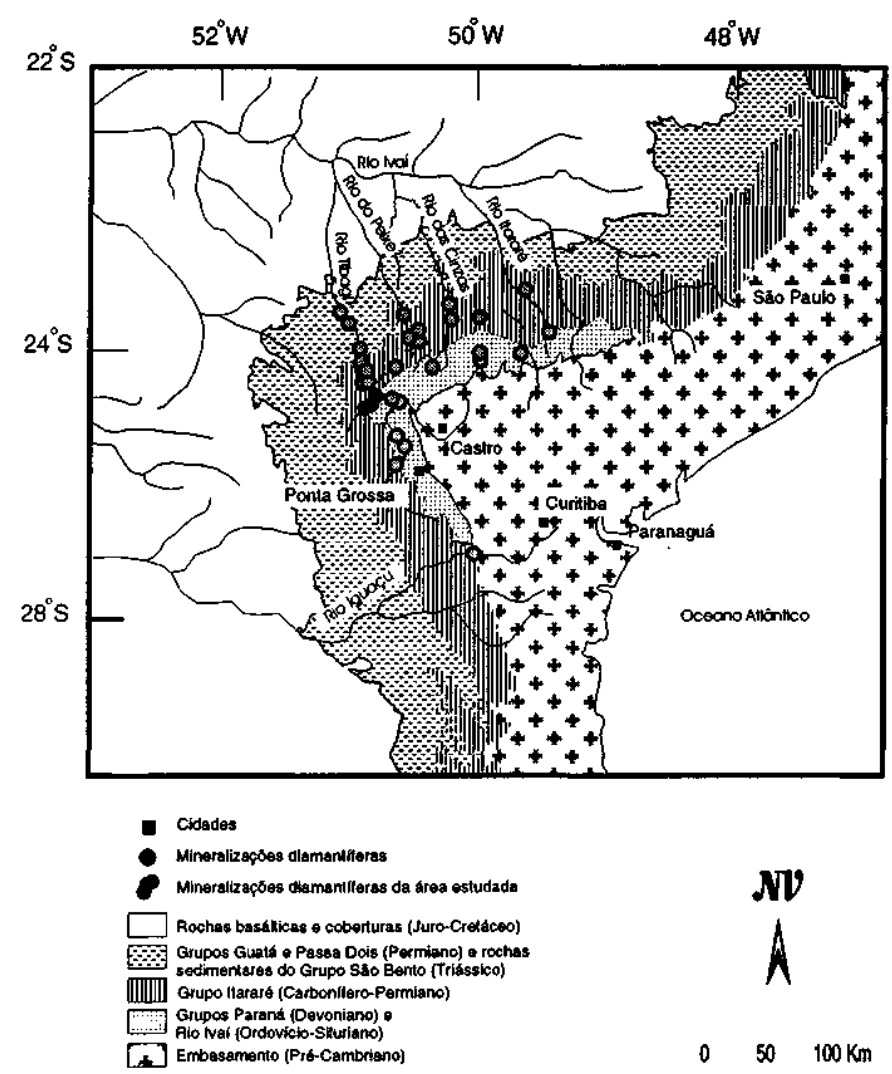

1] Embasamento (Prt-Cambriano

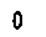

Figura 2 - Distribuição das mineralizações quaternárias de diamantes espacialmente associadas aos grupos Itararé e Paraná, na borda sudeste da Bacia do Paraná. (Mapa base modif. de Soares et al. (1995)).

que, tais inclusões seriam semelhantes àquelas presentes nos diamantes dos kimberlitos de Finsch, Koffiefontein e Premier (Á frica do Sul).

A forma predominante dos diamantes analisados é a tetrahexaédrica, com tendência a ocorrerem como cristais euédricos a subédricos (Fig.3 - Foto 1), de cor amarela clara e, secundariamente, incolor ou amarela escura (Tab. 1). As formas tetrahexaédricas observadas compreendem diamantes da classe 1 (Robinson et al. 1984 apud McCallum et al. 1991), ou seja do estágio mais avançado da reabsorção primária, no processo de conversão da forma octaédrica para a tetrahexaédrica. Diamantes com formas tetrahexaédricas, não especificada a classe, predominam, segundo Robinson et al. (1979 apud Gurney 1989), nos depósitos da região do Cráton Kaapvaal, no sudeste africano.

A presença de diamantes de formato próximo ao esférico e de tamanho médio pequeno (menores que $1 \mathrm{ct}$ ), com eventuais pedras maiores são feições que sugerem longo transporte e indicam distanciamento da área fonte (Sutherland 1982); enquanto que variações nas cores, formas dos cristais e tipos de diamantes são características de populações de diferentes fontes e de transporte seletivo, fazendo com que pedras ruins sejam destruídas e as de boa qualidade, preservadas. Também, pedras com formas tetrahexaédricas viajam mais longe que as octaédricas de mesma massa (Gurney 1989).

A curva de variação do tamanho dos diamantes com a distância de transporte fluvial e marinho (Fig.4), em relação à fonte primária, mostra uma redução acentuada na porção inicial, seguida de uma suavização ao longo da direção do transporte, onde pedras entre 1,0 e 2,0 ct não são transportadas a distâncias maiores que $30 \mathrm{Km}$ da área fonte primária, enquanto que pedras em torno de 0,1 ct são mais facilmente transportadas e podem ser encontradas até $650 \mathrm{Km}$ de sua fonte. O tamanho médio dos diamantes da região do rio Tibagi, entre 0,1 e 0,3 ct (Chieregati 1989), comparativamente aos dados de Sutherland (1982), indicam um transporte em torno de 150-200 Km o que implicaria na existência de kimberlitos a uma distância equivalente a esta, a montante da rede de drenagem atual (S-SE), caso a fonte fosse primária. Essa restrição não existiria se o transporte fosse por geleiras, uma vez que em sedimentos glaciogênicos a variação do tamanho das pedras não é um fator atrelado a distância do transporte, pois esses sedimentos estão distribuídos por toda a área mineralizada.

Durante o processo de transporte glacial, os sedimentos podem ser submetidos a consideráveis pressões e abrasão pelo peso do movimento do gelo. Esse processo pode criar texturas de superficie em grãos de areia transportados pelo gelo, tais como: fraturas conchoidais, degraus subparalelos, degraus em arcos, estriações paralelas, indentações irregulares, entre outras (Krinsley \& Donahue 1968). Os diamantes apresentam a característica de persistirem no registro sedimentar devido a sua alta dureza, pela alta resistência à ruptura, por sua estabilidade em condições ambientais de temperatura e pressão e pelo fato de serem quimicamente inertes. Por esta razão é dificil o desenvolvimento daquelas feições associadas a transporte glacial em diamantes; no entanto, podem ocorrer quebras, principalmente, por impacto, sendo que pedras esféricas resistem melhor ao impacto por percussão do que outras formas, tal como verificado por Kurz et al. (1987 apud Gurney 1989).

Em um dos exemplares dos diamantes descritos (Fig.3 - Foto 2) nota-se uma face do cristal tetrahexaédrico contendo sulcos paralelos, os quais poderiam configurar estrias de natureza glacial, e arestas gastas produzidas por abrasão no transporte fluvial. E provável que outras feições superficiais observadas nos cristais, tais como lascas (Fig.3 - Foto 3) e quebras (Fig.3 - Foto 4), tenham sido geradas por ruptura devida a impacto.

Algumas feições primárias de reabsorção estão presentes na maioria das amostras observadas, similares às descritas por McCallum et al (1991) nos diamantes do Distrito Colorado-Wyoming, destacando-se linhas de laminação (planos planares) (Fig.3 - Foto 5), laminação cruzada (Fig.3 - Foto 6) e muitas vezes textura shagreen (Fig.3 - Foto 7) associada. Estas feições derivam de deformação plástica, a qual é mais facilmente detectada em populacões com alta proporção de formas tetrahexaedróide (Urosovskaya; Orlov 1964 e Orlov 1973 apud Gurney 1989).

Minerais pesados associados aos depósitos A presença ou ausência de minerais em sedimentos varia de acordo com a sua disponibilidade na área fonte, granulometria original, resistência mecânica e química, forma e densidade, bem como intemperismo na área fonte, relação entre velocidade de erosão e intemperismo, tempo e meio de transporte e condições físico-químicas do meio deposicional, tal como observado por Chieregati (1989).

A assembleia mineralógica que normalmente está associada aos depósitos de diamantes no Estado do Paraná compreende fragmentos e nódulos de quartzo, jaspe, pirita, magnetita, limonita, anfíbólio, turmalina (preta e verde), anatásio (azul e amarelo claro), granada, ouro, e eventualmente platina, entre outros.

Cruz (1985) de acordo com Oppenheim (1936) identificou, na bacia hidrográfica do rio Tibagi, limonita, magnetita, cianita, jaspe, corindon turmalina, moscovita, diásporo, sillimanita, clorita e berilo.

Áreas mineralizadas na região do rio Tibagi-PR mostraram, segundo Chieregati et al. (1984), que a fração de pesados é composta por espinélio e/ou granada em quase $90 \%$ das amostras, e a ilmenita está presente em todas elas. Chieregati (1989) e Chieregati \& Svisero (1990) caracterizaram, além destes minerais, ouro, magnetita, zircão, cromita, piroxênio, hornblenda, epidoto, monazita, xenotima, fosfato, turmalina, rutilo, leucoxênio, anatásio, titanita, hematita, goethita, limonita e cassiterita. Reis \& Cunha Neto (1982) relatam a presença de ilmenita de rocha básica, anatásio, magnetita, hematita, limonita, cianita, jaspe, granada, corindon, turmalina, moscovita, diásporo, sillimanita, clorita e berilo.

Dentre a assembleia mineralógica presente não são identificados minerais indicadores de kimberlitos. A granada é essencialmente do tipo almandina e a ilmenita apresenta baixo teor de magnésio (Svisero 1994).

A suíte de minerais pesados do Grupo Itararé é caracterizada, segundo Wu (1981), pela presença de zircão, turmalina, rutilo, granada, monazita, estaurolita, apatita, moscovita, cianita, epidoto, magnetita, ilmenita e leucoxênio, além de limonita como fase amorfa, apresentando quartzo, feldspato como principais componentes leves, e fragmentos de rochas.

No mapa geológico e de litofácies da bacia do rio Santa Rosa (Fig. 5; Perdoncini 1997), estão representadas 4 unidades de associação de litofácies glaciogênicas, usando a terminologia da Eyles et al. (1983) da parte inferior do Grupo Itararé:

Unidade I, formada por 5 fácies: 1 - arenitos conglomeráticos com estratificação cruzada acanalada (St) e 2 - planar (Sp), 3 - conglomerado estratificado (Gp), 4 -conglomerado caótico (Ge) e 5 -arenitos gradados $(\mathrm{Sg})$. 


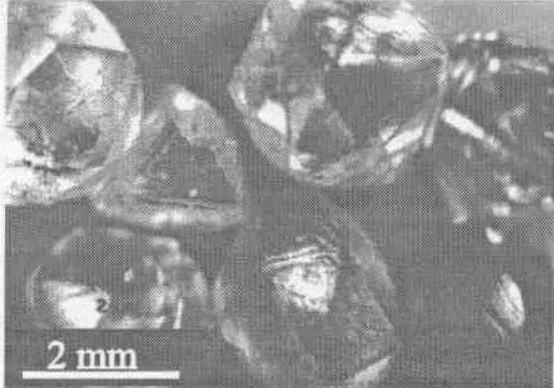

Foto 1

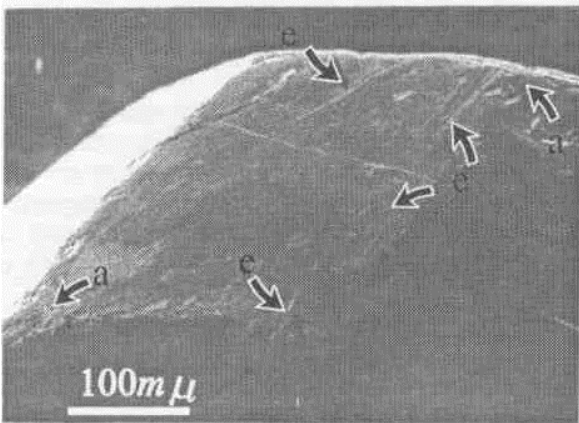

Foto 3

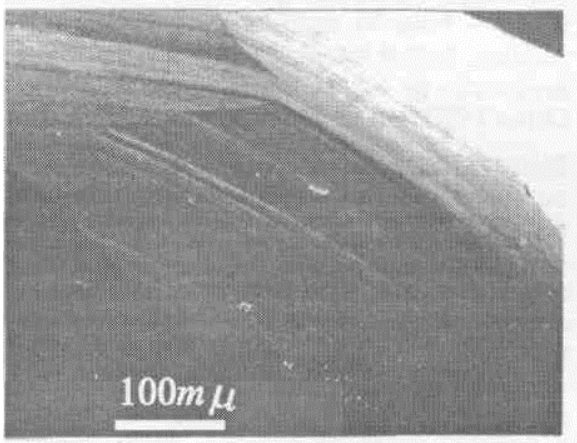

Foto 5

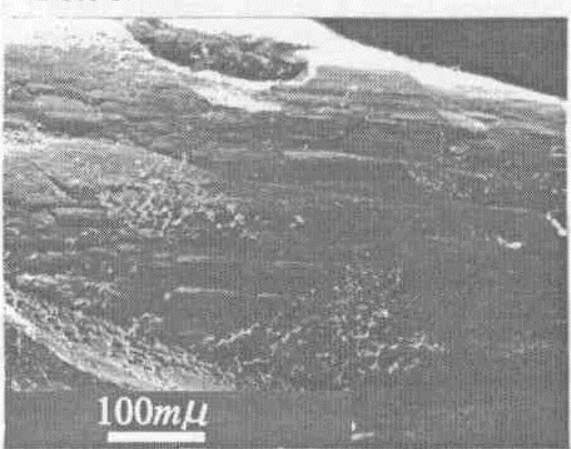

Foto 7

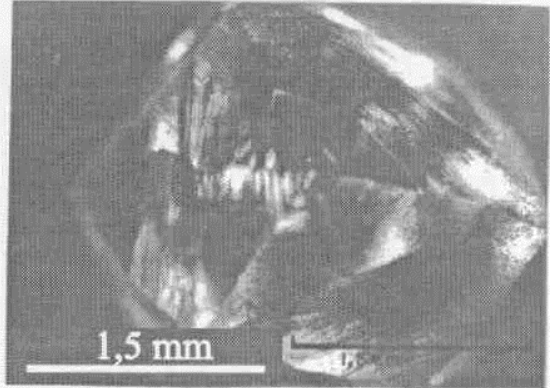

Foto 2

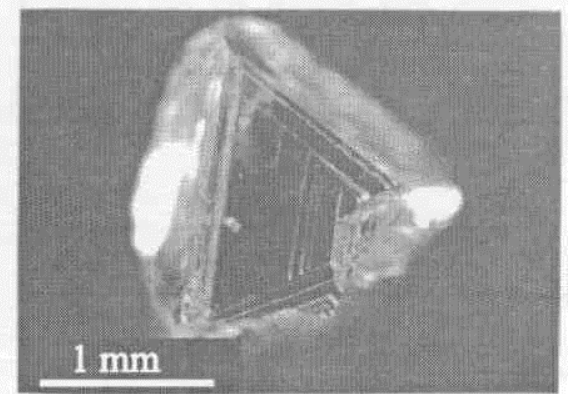

Foto 4

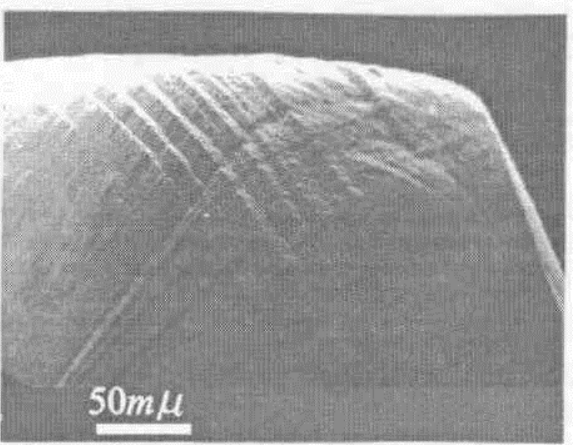

Foto 6

Figura 3 - Exemplares de diamantes da região do rio Tibagi, Paraná. Foto 1. Seis exemplares tetrahexaédricos e um octaédrico; Foto 2. Cristal euédrico (tetrahexaédrico), incolor, sem inclusões; Foto 3. Fotomicrografia eletrônica de uma face do diamante da foto 2, com estrias ou sulcos paralelos (e) e arestas (a) desgastadas, geradas por transporte fluvial ou glacial; Foto 4. Diamante octaédrico geminado (macla), apresentando quebra por impacto; Foto 5. Fotomicrografia eletrônica mostrando laminações paralelas, formadas por reabsorção primária; Foto 6. Fotomicrografia eletrônica mostrando laminações cruzadas, formadas por reabsorção primária; Foto 7. Fotomicrografia eletrônica mostrando textura shagreen, formada por reabsorção primária.

Unidade II, formada por 6 fácies: 1 - arenitos com marcas onduladas (Sr), 2 - arenitos maciços (Sm), 3 -diamictitos maciços com matriz lamítica (Dmm, ressedimentados (r)); 4 - arenitos gradados (Sg), 5 -pelitos laminados $(\mathrm{Fl})$ e 6 - pelitos laminados com seixos esparsos (Fld);

Unidade III, formada por 2 fácies: 1 -arenitos maciços (Sm) e 2 arenitos gradados $(\mathrm{Sg})$;

Unidade IV, formada por 3 fácies: 1 -conglomerados maciços $(\mathrm{Gm}$, ressedimentados (r)), 2 -arenitos maciços (Sm, ressedimentados (r)) e 3 - arenitos gradados $(\mathrm{Sg})$.
Nas fácies St/Sp, Gp e Gm(r)), das unidades I e IV, nas frações granulométricas entre 0,250 a $0,125 \mathrm{~mm}$, verificou-se uma predominância de minerais pesados estáveis como zircão, turmalina e rutilo, secundariamente, leucoxênio, cianita, estaurolita, hiperstênio, pistacita, hornblenda, sillimanita, alteritos, e, raramente, granada e monazita (Tab. 2). Corpos de conglomerados caóticos (fácies Gc), que ocorrem associados aos sedimentos basais, mostram um predomínio de seixos de arenito, com composição variável (35-50\%), secundado por seixos de quartzo $(20-30 \%)$ e de quartzito $(15-25 \%)$, e subordinadamente seixos de siltito, granito e argilito. 
Em garimpos situados no rio Santa Rosa, os concentrados de bateia revelam uma composição mineralógica/litológica, na fração seixos e grânulos, em ordem decrescente, composta de: quartzo, limonita, ilmenita, metarenito, basalto e magnetita. Grãos de rocha básica, goetita, pirita e limonita apresentam baixo grau de arredondamento.

Tal como esperado, a contribuição do Grupo Itararé, como fonte dos aluviões mineralizados, fica evidente pela presença de minerais e rochas dos sedimentos permo-carboníferos nos depósitos diamantíferos, tais como: zircão, turmalina, rutilo, granada, ilmenita, leucoxênio, hornblenda, epídoto, magnetita, sillimanita, monazita, seixos de quartzo e de granito, siltito, quartzito e arenito de composições variadas, embora a assembleia de minerais ultraestáveis (ZTR) e alguns seixos de quartzo/quartzito sejam também compartilhados pela Formação Furnas. Além desta assembleia mineralógica do Itararé, a parte acrescentada a partir de rochas mais jovens é resultante de minerais das rochas básicas dos diques e sills da área (ilmenita, magnetita, pirita e goethita).

FONTE DOS ALUVIÕES DIAMANTÍFEROS A erosão de rochas kimberlíticas ou lamproíticas diamantíferas libera os diamantes que, devido a sua alta dureza e resistência química, tendem a persistir no registro sedimentar sob a forma de depósitos detríticos ou pláceres diamantíferos. Esses pláceres, segundo Smirnov (1982), podem ser diferenciados em: i) eluviais; ii) diluviais (coluviais pouco transportados); iii) proluviais (coluviais de sopé); iv) fluviais ou aluviais; v) ct/st

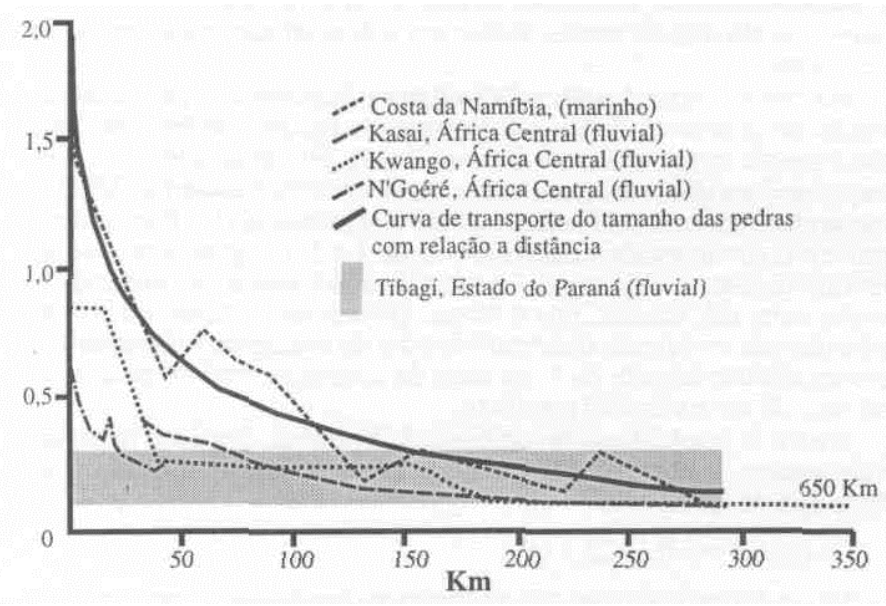

Figura 4 - Variação do tamanho médio dos diamantes com a distância de transporte por processos fluvial e marinho (ct/st = quilate por pedra); modificado de Sutherland (1982). praiais; vi) glaciais e vii) eólicos. Podem constituir depósitos detríticos jovens ou antigos (paleopláceres). Como exemplo, Weska et al. (1993) citam a presença de diamantes em garimpos desenvolvidos em cascalhos eluviais e em conglomerados in sim nas formações Quilombinho e Cachoeira do Bom Jardim, Grupo Bauru (Poxoréo-MT). Pláceres diamantíferos formados por deflação (pláceres eólicos) estão presentes no deserto da Namíbia (Smirnov 1982). Pláceres diamantíferos eólicos e marinhos na planície costeira atlântica da África do Sul e Namíbia (Rouffaer 1988) resultam de depósitos fluviais retrabalhados por ação élica ou de ondas marinhas, concentrados em superficies de deflação e de abrasão respectivamente.

Água e gelo são os principais transportadores e distribuidores de diamantes, podendo agir como agentes diluidores ou concentradores, dependendo dos processos de transporte. Em sistemas fluviais ocorre uma sensível diminuição de tamanho das pedras quanto maior a distância do transporte. Glaciares continentais, por serem um meio de transporte não seletivo, podem transportar, por fluxo de massa, diamantes e minerais pesados por toda a extensão de seu fluxo, podendo atingir longas distâncias.

Os depósitos detríticos de diamantes são considerados economicamente mais fracos que depósitos primários. A tendência geral nos processos de erosão e transporte é a de ocorrer dispersão com diluição de teores. Entretanto processos particulares de transporte e deposição, como em lags aluviais, superfícies de abrasão e de deflação, podem promover elevada concentração em volumes significativos.

Grande parte da produção mundial e brasileira de diamantes naturais é de origem detrítica, indicando que os processos sedimentares são eficientes na formação de depósitos secundários. Paralelamente, observa-se que os diamantes aluviais são, em média, de melhor qualidade que os de fontes primárias (Sutherland 1982), mostrando a importância desse tipo de depósito.

Tabela $l$ - Descrição das características dos diamantes analisados da bacia do rio Tibagi, Paraná.

\begin{tabular}{|c|c|c|c|c|}
\hline Exiemplat & Forma & Cor & Inctureses & \\
\hline 1 & 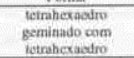 & incolor & ausente & $\begin{array}{l}\text { Faces antronondatass } \\
(0,11 \text { a) }\end{array}$ \\
\hline 2 & $\begin{array}{l}\text { octacdrog genninulo } \\
\text { com extaction }\end{array}$ & incolor & meserte & 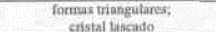 \\
\hline$\frac{2}{3}$ & thrahoradto & castantas & prescerse. & 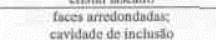 \\
\hline 4 & $\begin{array}{l}\text { tetratecacicdro mal. } \\
\text { formado }\end{array}$ & incolor & presenche & faces arredondadass \\
\hline 5 & imegulat & incolor & presenese & faces anedondadas \\
\hline 6 & $\begin{array}{l}\text { Tetrahocasedro } \\
\text { imegular }\end{array}$ & aminedo claro & presermic & presenga de fices de letraherviefirn \\
\hline 7 & Teiratherescidro & anarelo claso & presenter & faces anzidondadar \\
\hline $\bar{k}$ & 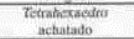 & andarcho clana & prevente & F \\
\hline 9 & $\begin{array}{l}\text { Tetribiboxzedro } \\
\text { incrulatr }\end{array}$ & atnarelo claro & atsentice & . \\
\hline 10 & $\begin{array}{l}\text { Tetrabectecidos } \\
\text { incenular }\end{array}$ & amierto claro a incolor & presente & 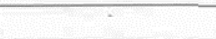 \\
\hline 11 & $\begin{array}{l}\text { Ietrabenanadro } \\
\text { ullongado }\end{array}$ & incolar & ausentce & . \\
\hline
\end{tabular}

Tabela 2 - Minerais pesados do Grupo Itararé e dos sedimentos aluvionares da bacia mineralizada do rio Santa Rosa, Estado do Paraná.

\begin{tabular}{|c|c|c|c|c|c|c|c|c|c|c|c|c|c|c|c|c|c|c|}
\hline AMOSTRA & AMPER & ZIRCAOO & TURMAL & RUTILO & APATTTA & ESTAUR. & $\begin{array}{c}\text { GRANAD } \\
\mathrm{A}\end{array}$ & PISTACH. & ClANTA & SILLIMAN & BARITA & HORNBL & HIPERS & ANDALUZ & MONAZIT & LEUCOX & \begin{tabular}{|l|} 
ALTE \\
RITO \\
\end{tabular} & $\begin{array}{c}\text { OPACO } \\
(0-100 \%)\end{array}$ \\
\hline AM 1 & \begin{tabular}{|}
$1,0 \mathrm{~A}$ \\
$+1,0 \mathrm{~A}$ \\
$+0,6 \mathrm{~A}$
\end{tabular} & $\bar{P}$ & $\begin{array}{l}\mathrm{P} \\
\mathrm{M}\end{array}$ & $\begin{array}{l}\mathrm{T} \\
\mathrm{T}\end{array}$ & & $\begin{array}{l}\mathrm{T} \\
\mathrm{T}\end{array}$ & & $\bar{T}$ & $\begin{array}{l}\mathrm{T} \\
\mathrm{T}\end{array}$ & & & $T$ & M & & & $\begin{array}{l}\mathrm{T} \\
\mathrm{E}\end{array}$ & $T$ & $\begin{array}{l}\mathrm{P} \\
\mathrm{P} \\
\mathrm{P}\end{array}$ \\
\hline AM 2 & \begin{tabular}{|}
$-1,0 \mathrm{~A}$ \\
$+1,0 \mathrm{~A}$ \\
$+0,6 \mathrm{~A}$ \\
\end{tabular} & $\begin{array}{l}\mathrm{A} \\
\mathrm{T} \\
\mathrm{T}\end{array}$ & $\begin{array}{l}\mathrm{T} \\
\mathrm{P} \\
\mathrm{A}\end{array}$ & $\begin{array}{l}\mathrm{A} \\
\mathrm{T}\end{array}$ & & & & & $\begin{array}{l}\mathrm{T} \\
\mathrm{T} \\
\mathrm{M}\end{array}$ & & & $T$ & M & & & E & & $\begin{array}{l}\mathrm{M} \\
\mathrm{A} \\
\mathrm{P}\end{array}$ \\
\hline AM 3 & $\begin{array}{r}1,0 \mathrm{~A} \\
+1,0 \mathrm{~A} \\
+0,6 \mathrm{~A} \\
\end{array}$ & P & $\begin{array}{l}E \\
T\end{array}$ & A & & & & $T$ & $\mathrm{~T}$ & & & & & & & $\begin{array}{l}\mathrm{P} \\
\mathrm{M} \\
\mathrm{P}\end{array}$ & & $\begin{array}{l}\mathrm{M} \\
\mathrm{A} \\
\mathrm{P}\end{array}$ \\
\hline AM 4 & $\begin{array}{r}-1,0 \mathrm{~A} \\
+1,0 \mathrm{~A} \\
+0,6 \mathrm{~A} \\
\end{array}$ & $M$ & $\begin{array}{l}T \\
\mathrm{~A} \\
\mathrm{P}\end{array}$ & $T$ & & $\mathrm{~T}$ & & & T & $T$ & & & & & & $\begin{array}{l}\mathrm{T} \\
\mathrm{E} \\
\mathrm{T}\end{array}$ & & $\begin{array}{l}\mathrm{M} \\
\mathrm{P} \\
\mathrm{E}\end{array}$ \\
\hline AM 5 & $\begin{array}{r}1,0 \mathrm{~A} \\
+1,0 \mathrm{~A} \\
+0,6 \mathrm{~A} \\
\end{array}$ & $\begin{array}{l}\mathrm{P} \\
\mathrm{T} \\
\mathrm{T}\end{array}$ & $\begin{array}{l}\mathrm{P} \\
\mathrm{M}\end{array}$ & $\begin{array}{l}\mathrm{A} \\
\mathrm{T}\end{array}$ & & $T$ & $T$ & & $\mathrm{~T}$ & & & & & & & $\begin{array}{l}\mathrm{T} \\
\mathrm{T} \\
\mathrm{P}\end{array}$ & $\mathrm{T}$ & $\begin{array}{l}\mathrm{E} \\
\mathrm{A} \\
\mathrm{P}\end{array}$ \\
\hline AM 6 & \begin{tabular}{|}
$1,0 \mathrm{~A}$ \\
$+1,0 \mathrm{~A}$ \\
$+0,6 \mathrm{~A}$
\end{tabular} & $\begin{array}{l}\mathrm{P} \\
\mathrm{T} \\
\mathrm{T}\end{array}$ & $\begin{array}{l}\mathrm{P} \\
\mathrm{P}\end{array}$ & $\mathrm{M}$ & & $\mathrm{T}$ & & & $\mathrm{T}$ & & & & $T$ & & $\mathrm{~T}$ & $\begin{array}{c}\text { M } \\
\mathrm{E}\end{array}$ & & $\begin{array}{l}\mathrm{E} \\
\mathrm{P} \\
\mathrm{P}\end{array}$ \\
\hline $\mathrm{AM} 7$ & \begin{tabular}{|l|}
$-1,0 \mathrm{~A}$ \\
$+1,0 \mathrm{~A}$ \\
$+0,6 \mathrm{~A}$ \\
\end{tabular} & $\mathrm{P}$ & $\begin{array}{l}\mathrm{P} \\
\mathrm{P}\end{array}$ & $T$ & & & & & & & & & & & & $\begin{array}{l}\mathrm{M} \\
\mathrm{M}\end{array}$ & $\begin{array}{l}\mathrm{T} \\
\mathrm{T}\end{array}$ & $\begin{array}{l}\mathrm{P} \\
\mathrm{P} \\
\mathrm{P}\end{array}$ \\
\hline AM 8 & $\begin{array}{c}-1,0 \mathrm{~A} \\
+1,0 \mathrm{~A} \\
+0,6 \mathrm{~A}\end{array}$ & $\begin{array}{l}P \\
\mathrm{~T}\end{array}$ & $\begin{array}{l}T \\
P \\
P\end{array}$ & $M$ & & & & & $T$ & & & & & & & $\begin{array}{l}\mathrm{A} \\
\mathrm{M} \\
\mathrm{E}\end{array}$ & $T$ & $\begin{array}{l}\mathrm{A} \\
\mathrm{P} \\
\mathrm{P}\end{array}$ \\
\hline AM 9 & $\begin{array}{c}-1,0 \mathrm{~A} \\
+1,0 \mathrm{~A} \\
+0,6 \mathrm{~A}\end{array}$ & P & $\mathrm{P}$ & & & & & & $\mathrm{T}$ & & & & & & $T$ & A & & $\begin{array}{l}\text { E } \\
\text { A } \\
\text { P }\end{array}$ \\
\hline
\end{tabular}

*P - predominante $(60$ a $80 \%)$ A - abundante $(40$ a $60 \%)$

$\overline{\mathrm{M}}$ - moderado $(20 \mathrm{a} 40 \%)$

E- escasso $(5$ a $20 \%) \mathrm{T}-\operatorname{traço~}(<5 \%)$

'Amostra: 1-sedimento de corrente; 2-conglomerado caótico basal (fácies Ge); 3 a 8-conglomcrado estratificado basal (fácies Gp); 9-conglomerado maciço de topo

(fácies Gm(r)). Para identificação das fácies, veja Pcrdoncini (1997). 
Conglomerados basais resultantes de cargas de leito são as fácies preferenciais para concentração do diamante, sendo a configuração do leito um fator controlador dos depósitos de diamantes e o tamanho médio da população de diamantes está relacionada a energia hidráulica do meio transportador revelada pelo tamanho dos seixos.

As rochas hospedeiras de diamantes podem consistir cascalhos coluviais e aluviais de diferentes idades, os quais desenvolvem-se durante a evolução da drenagem. Quando consolidadas, formam arenitos conglomeráticos e conglomerados diamantíferos, tais como os da Formação Arai, em Roraima (Souza 1993). Estes arenitos conglomeráticos e conglomerados, por sua vez, podem ser retrabalhados e alimentar aluviões recentes.

Extensas áreas aluviais diamantíferas possuem como áreas-fonte rochas glaciais, tais como no sudoeste do Transvaal, que é parcialmente mineralizada pelo retrabalhamento dos tilitos Dwyka, na África do Sul; no oeste australiano ocorrem testemunhos da glaciação permiana, a qual têm provavelmente contribuído com a produção diamantífera de pláceres daquele país (Atkinson 1989).

A associação de diamantes com sedimentos glaciogênicos de diferentes idades foi verificada em diversas regiões do Brasil por Oppenheim (1943), Tompkins \& Gonzaga (1989), Gonzaga \& Tompkins (1991), Gonzaga \& Dardene (1991), Campos et al. (1993), Gonzaga (1994)eSvisero(1994).

Tal como ressaltado por Smimov (1982), os mecanismos de transporte e deposição pela ação de geleiras não são processos seletivos, de forma que os depósitos de tilito não apresentam bom potencial para mineralização. Entretanto, a ação de moagem exercida pelo gelo pode ocorrer na forma de um processo de cominuição diferencial onde fragmentos líticos vão sendo desgastados e moídos formando clastos finos (silte + argila + areia), e os elementos mais resistentes tanto mineral (diamante/quartzo) como rocha (quartzito) ficam preservados, resultando num enriquecimento relativo em diamantes na fração grossa.

Melhores condições de formação de pláceres diamantíferos ocorrem em depósitos flúvio-glaciais gerados a partir de água de degelo. Destacam-se as fácies sedimentares terrestres, devido ao seu caráter trativo, que podem concentrar clastos e cristais preservados e dispersos nas geleiras. Fácies de alta energia incluem depósitos de canais fluviais subglaciais (eskers), os quais podem passar para depósitos fluviais periglaciais de alta energia (outwashs). Rios de degelo são em geral do tipo entrelaçado, de baixa sinuosidade, cujos grãos são de tamanho cascalho próximo à fonte e passam para areia e silte nas porções distais (Miall 1983).

Canais englaciais e fácies fluviais de ambiente supraglacial podem apresentar características de alto nível energético iguais àquelas de ambiente subglaciais, concentrando, eventualmente, diamantes; porém dificilmente preservam as fácies no registro geológico. Outro fator responsável pela concentração de diamantes em sedimentos glaciogênicos é o retrabalhamento sedimentar durante períodos interglaciais.

A alta capacidade de concentração de algumas fácies glaciais/glaciogênicas pode ser notada, de acordo com Eyles \& Kocsis (1988a, b), no Distrito Mineiro Cariboo (Canadá), onde ocorrem dois tipos de pláceres auríferos: i), pláceres derivados de sistemas fluviais anteriores à glaciação Wiscosiniana e ii) pláceres resultantes do retrabalhamento de cascalhos glaciais auríferos, onde as atividades fluviais e glaciais recentes têm concentrado o ouro dos depósitos aluvionares antigos.

As mineralizações diamantíferas na bacia do rio Santa Rosa ocorrem nas áreas do salto Santa Rosa, do arroio Água dos Borges, nas imediações do Bairro Lavras e no local denominado de Pedra Branca (Fig. 5), onde afloram sedimentos areno-conglomeráticos da parte inferior do Grupo Itararé e pelíticos da Formação Ponta Grossa.

O Grupo Itararé está aí representado pelas quatro unidades de associações de fácies mapeadas, constituídas predominantemente por arenitos conglomeráticos, conglomerados e arenitos maciços (Perdoncini \& Soares 1996, Perdoncini 1997 ).

Arenitos conglomeráticos estratificados (St/Sp) e conglomerados estratificados suportados ora pêlos clastos ora pela matriz arenosa (Gp), em corpos lenticulares interdigitados predominam na Unidade I. Os seixos arredondados, facetados, achatados e localmente imbricados variam de $1 \mathrm{~cm}$ a $0,50 \mathrm{~m}$ e são compostos de siltitos, arenitos, quartzitos, pelitos e granitos. Por vezes, ocorrem conglomerados caóti$\cos (\mathrm{Ge})$ preenchendo paleocanais que aparecem incisos nestas fácies.

Sobre este pacote ocorrem arenitos finos $(\mathrm{Sg})$ bem selecionados que gradam para pelitos (Fl) por vezes seixosos (Fld), diamictitos $(\mathrm{Dmm}(\mathrm{r}))$ arenitos finos maciços $(\mathrm{Sm})$ a levemente estratificados e com marcas onduladas (Sr) (Unidade II). Sobrepõem-se espessos pacotes de arenitos maciços $(\mathrm{Sm})$ e arenitos gradados $(\mathrm{Sg})$ (Unidade III).

Acima destas unidades ocorre um novo pacote de conglomerado polimítico $(\mathrm{Gm}(\mathrm{r}))$ grosso associado a arenitos maciços $(\mathrm{Sm})$ e gradados (Sg) (Unidade IV), mineralogicamente similar ao pacote basal.

Todas estas associações faciológicas são produto de sedimentação em ambiente periglacial, formado por leques de degelo subaéreos (outwash fan), depositados parcialmente num corpo aquoso. A unidade basal foi depositada por canais braided, cuja interdigitação desenvolvida nas frentes de outwash gerou as fácies arenosas e conglomeráticas.

Conforme visto anteriormente, fácies conglomeráticas basais configuram as principais fácies com bom potencial na formação de depósitos detríticos diamantíferos, enquanto que, para a formação desses depósitos secundários é necessária a atuação de processos sedimentares trativos ou a existência de uma pré-concentração de diamantes remobilizada por qualquer outro processo sedimentar. Entretanto, os processo de ressedimentação apresentam a tendência de diluir as concentrações detríticas.

Dessa forma, na caracterização da potencialidade das fácies conglomeráticas de alta energia como fonte intermediária dos diamantes, da bacia do rio Santa Rosa, foi considerado o inter-relacionamento entre o grau de maturidade textural e mineralógica dos sedimentos e o tipo de processo deposicional (Fig. 6), onde quanto maior a maturidade e, secundariamente, a presença de estratificação cruzada indicadora de depósitos aluviais de canais, maior seu potencial para gerar depósitos detríticos.

$\mathrm{Na}$ classificação dos tipos faciológicos preferenciais para concentração de diamantes foram selecionadas as fácies conglomeráticas e estabelecida uma medida de favorabilidade $(\mathrm{F})$, resultante da combinação de 3 variáveis independentes: maturidade mineralógica (MML), maturidade textural (MT) e ação de processos trativos $(f)$. Para as duas primeiras foram estabelecidos escores de 1 a 5 , em grau crescente de favorabilidade, considerando a classificação visual de maturidade como nula, má, regular, boa e ótima. Quanto ao processo trativo foi considerado ser apenas fator modificador da categoria, reduzindo seu escore arbitrariamente de 1 , no caso de transporte trativo, para 0,75 , no caso de ser transporte por fluxo.

Assim, o resultado de favorabilidade é produto das duas variáveis independentes, normalizado para o máximo valor, modificado pelo fator tipo de transporte:

\section{$\mathrm{F}=(\mathrm{MT} \times \mathrm{MML}) / 25 \times(f)$}

Dessa forma infere-se que as fácies mineralizadas compreendem três classes principais de conglomerados, correspondentes aos campos 1,2 e 3 da figura 6. Cada campo compõe litologias com características distintas em termos de maturidade textural, maturidade mineralógica/litológica e presença ou ausência de estratificação cruzada.

Classe i) - composta por: a) conglomerado com matriz arenosa, com as propriedades maturidade textural e maturidade mineralógica/litológica classificadas como ótimas, com estrutura cruzada ou maciça; (b) conglomerado com matriz arenosa, com as propriedades maturidade textural classificada como boa e maturidade mineralógica/litológica classificadas como ótima, com estrutura cruzada; (c) conglomerado com matriz arenosa, com as propriedades maturidade textural classificada como ótima e maturidade mineralógica/litológica classificadas como boa, com estrutura cruzada (campo 1);

Classe ii) Composta por conglomerados com matriz arenosa, com maturidade textural e/ou mineralógica/litológica ótima a regular, maciços ou com estratificação cruzada (campo 2);

Classe iii) Composta por conglomerado com matriz arenosa, com maturidade mineralógica/litológica boa, maciço, ou conglomerados com maturidade mineralógica/litológica ótima a má inversamente proporcional à maturidade textural, maciços ou com estratificação cruzada (campo 3).

Com base no exposto acima, a porção basal do Grupo Itararé (Unidade I), na área estudada, que é marcada por fácies conglomeráticas basais (campo 1) sedimentadas em regime trativo e com ótima a boa maturidade textural e mineralógica/litológica, configura potencialmente a unidade preferencial como portadora de diamantes, seguidas das fácies conglomeráticas ressedimentadas $(\mathrm{Gm}(\mathrm{r}))$ da Unidade IV.

Além destas características, os dados de paleocorrentes, segundo Bigarella(1973) e França et. al. (1996), mostram que, na borda oriental da Bacia do Paraná, as geleiras movimentaram-se de sul-sudeste para norte-noroeste, enquanto que o Lobo Kaokoveld, de França \& Potter 


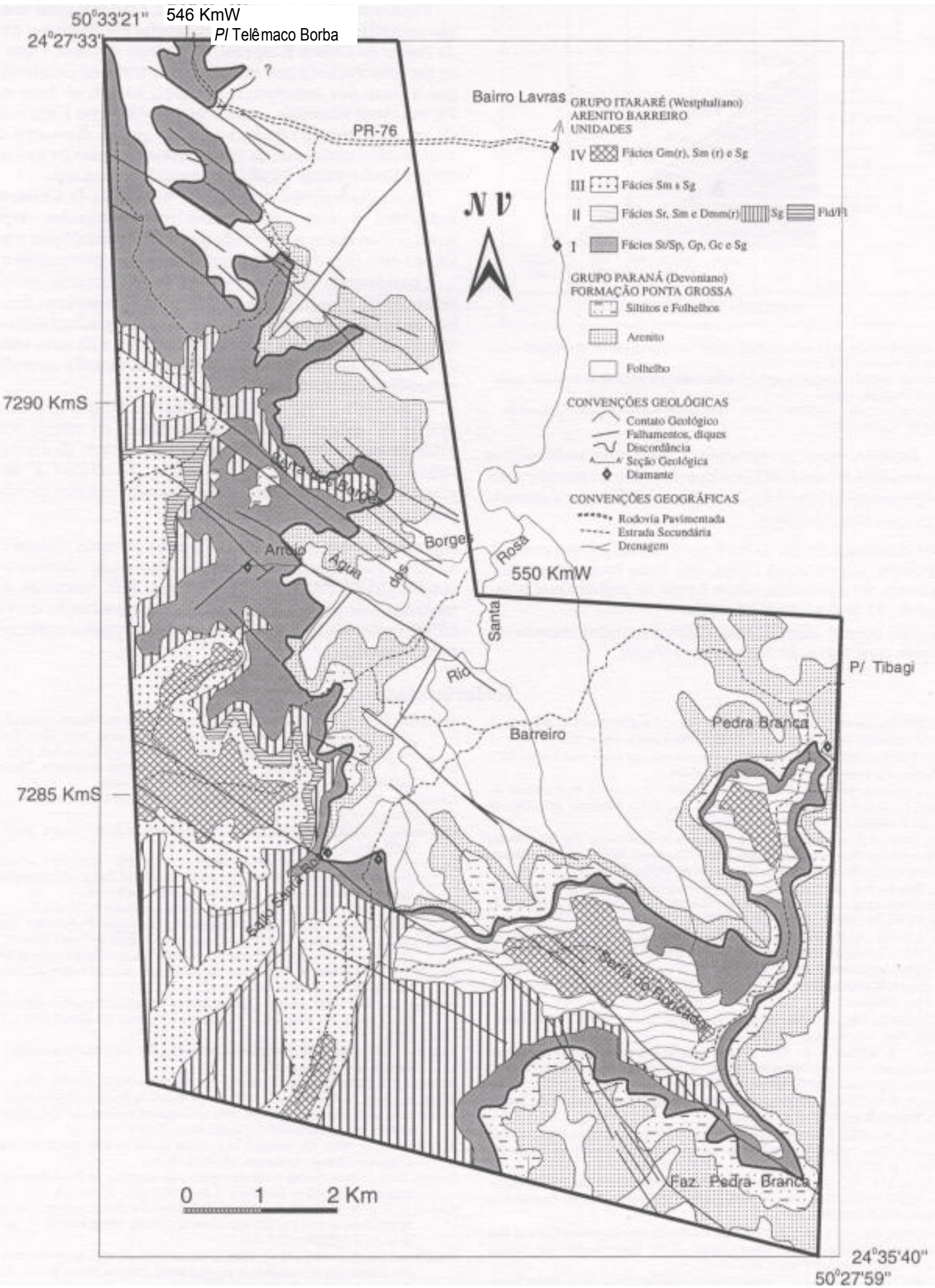

Figura 5 - Mapa geológico e ocorrências de diamante na área da bacia do rio Santa Rosa, Estado do Paraná, segundo Perdoncini (1997).

(1988), oriundo do sul do atual continente africano, onde ocorrem corpos primários mineralizados a diamante, é o principal agente transportador dos sedimentos Itararé.

CONCLUSÕES Duas principais teorias são discutidas para a origem das ocorrências de diamantes no Estado do Paraná: i) uma associada à glaciação permo-carbonífera; ii)outra associada a fontes primárias. A mineralização ocorre basicamente em áreas onde afloram os sedimentos de idade devoniana a permiana da Bacia do Paraná, em especial nas áreas de domínio dos sedimentos do Grupo Itararé, tanto na porção ocidental como oriental da bacia. Não são conhecidas fontes primárias na região nem minerais satélites que indiquem proximidade de tais fontes. Ao contrário, a assembleia de pesados é compatível com aquela do Grupo Itararé, acrescida apenas de minerais comuns aos diques de diabásio.

Os estudos mostraram que os conglomerados trativos basais e de topo (ressedimentados) da área estudada seriam as fontes inter- 


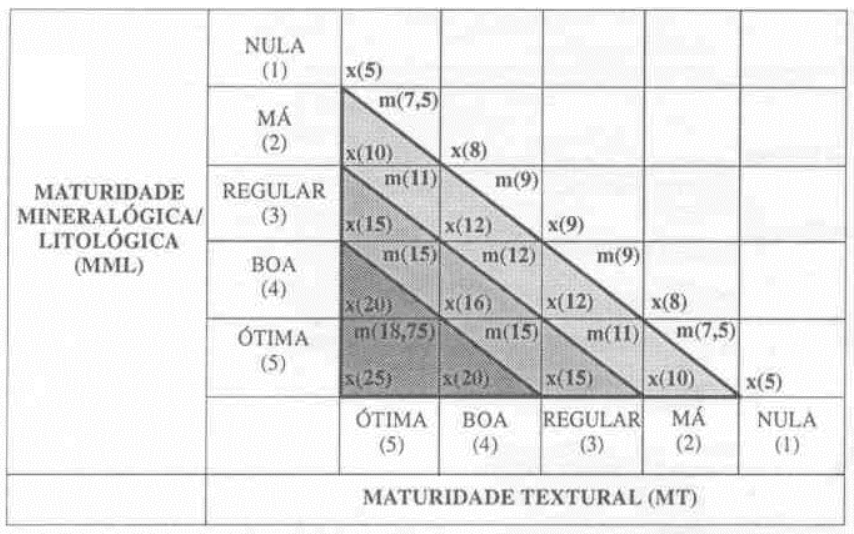

campo I (conglomerado de primeira ordem) - valor médio em torno de 20 configura rocha hospedeira de primeira ordem: campo 2 (conglomerado de segunda ordem - valor médio em torno de 15 configura rocha hospedeira de segunda ordem; campo 3 (conglomerado de segunda ordem) - valor médio inferior a 12 configura rocha hospedeira de terceira ordem.

Figura 6 - Relação entre a maturidade mineralógico/litológica (MML), a maturidade textural (MT) e o tipo de processo deposicional $(x, m)$ de conglomerados, com relação afavorabilidade para concentração de diamante/ouro detrítico.

mediarias dos diamantes do rio Santa Rosa e, consequentemente, do rio Tibagi. Recomenda-se, dessa forma, que essas fácies sejam pesquisadas na busca de diamantes, como forma de redirecionar a exploração e produção de diamantes na região.

A análise das feições morfoscópicas dos diamantes mostrou-se insuficiente para caracterização de transporte glacial.

Atkinson, W. J. 1989. Diamond exploration, philosophy, practicc and promiscs: a review In: J. Ross (cd) Kimhertites and related rocks. Victoria, Blackwcll Science, 2:1075-1107.

Bigarclla, J. J. 1973. Paleocorrcntes c deriva continental: comparação entre América do Sul e África. Boletim Paranaense de Geociências, 31:14-224.

Campos, J. E. G., Dardenc, M. A. \& Gon/.aga, G. M. 1993. O potencial diamantífero do Conglomerado Abaete no NW de Minas Gerais. In: SBG, Simpósio Brasileiro de Geologia do Diamante,1, Cuiabá, Anais; p. 101-113.

Chieregati, L. A. 1989. Aspectos mineralógicos, genéticos e económicos das ocorrência diamantiferas da região nordeste do Paraná e sul de São Paulo. Instituto de Geociências, Universidade de São Paulo, São Paulo, Dissertação de Mestrado, 180 p.

Chieregati, L. A., Svisero, D. P. \& Carmo, S. L. 1984. Ocorrências de diamante do Rio Tibagi áreas adjacentes: Estágio atual dos conhecimentos. In: SBG, Congresso Brasileiro de Geologia, 33, Rio de Janeiro, Anais, 8:3866-3876.

Chieregati, L. A. \& Sviscro, D. P. 1990. Estudo de minerais pesados da região diamantífera do rio Tibagi $(\mathrm{PR})$ e as possibilidades de existência de fontes primárias de diamante na região. Acta Geológica Leopoldensia, 13(10): 171-186.

Cru/., A. S. 1985. Projeto Diamante: reconhecimento regional; Curitiba: MINEROPAR (relatório interno), $31 \mathrm{p}, 5$ mapas.

Derby, O. A. 1878. The gcology of lhe diamantiferous region of lhe Province of Paraná, Brazil. Proc. Amer. Phyt. Soe., St. Paul, 18(102):251-258.

Eylcs, N. C., Eyles, C. H. \& Miall, A. D. 1983. Lithofacics typcs and vertical profilc models: an alternative approach to the description and environmental interpretation of glacial diamict and diamictitc sequenccs. Setlimentology 30:393-41Q.

Eyles, N. \& Kocsis, S. P. 1988a. Gold placcrs in Plcistoccnc glacial deposits; Barkcrvillc, British Columbia. CIM Bulletin, 81(916):71-79.

Eylcs, N. \& Kocsis, S. P. 1988b. Sedimentological conlrols on gold distribution in plcistocen placer deposits of the Cariboo Mining District, British Columbia. Geological Fieldwork, Paper 1989-1. p. 377-385.

França, A. B. \& Potter, P. E. 1988. Estratigrafia, ambiente deposicional e análise de reservatório do Grupo Itararé (Pcrmo-Carbonífero), Bacia do Paraná (Parte I). Boletim Geociências da Petrobrás, 2(2/4): 147-191.

França, A. B. et al. 1996. Arenitos Lapa-Vila Velha: um modelo de trato de sistemas subaquosos canal-lobos sob influência glacial, Grupo Itararé (C-P), Bacia do Paraná). Revista Brasileira de Geociências São Paulo, 26(1):43-56.

Gonzaga, G. M. 1994. Glaciação Nco-Ordoviciana (lapó/Vila Maria): Uma das prováveis fontes dos diamantes da Formação Furnas da Bacia do Paraná. In: SBG, Simpósio de Geologia do Centro-Ocstc, 4, Brasília, Anais, p. 47-49.

Gonzaga G. M. \& Dardenne, M. A. 1991. The Jequitai glaciation and the dispersion of diamonds during Upper Proterozoic. In: International Kimberlitc Conference 5, Araxá,. Resumo Expandido, p.89-93.

Gonzaga, G. M \& Tompkins, L. A. 1991. Geologia do diamante. In: Principais Depósitos Minerais do Brasil. Brasília, DNPM-CPRM, 4:53-116.

Gurncy, J. J. 1989. The mantle/crust setting, diamonds and diamond exploration In: J. Ross (cd.) Kimberlites and Related Rocks. Victoria, Blackwell Science, 2:935-965.

Krinslcy, D. H. \& Donahuc, J. C. 1968. Environmental interpretation of sand grain surface texturcs by Electron Microscopy. Geol. Soe. Am Bull., 79:743-748.

Maack, R. 1968. Diamante no tilito de Tibagi, Paraná. Anais da Academia Brasileira Ciências, 40:96. (Suplemento).
Considerando que algumas feições morfoscópicas dos diamantes são compatíveis com aquelas encontradas em diamantes dos depósitos da região do Cráton Kaapvaal, no sudeste africano, e que os padrões de movimentação de geleiras de sul para norte, no Gondwana, mostram que a fonte dos sedimentos do Grupo Itararé, no leste da Bacia do Paraná esteja associada a movimentação do Lobo Kaokoveld, oriundo do sul da Âfrica, é razoável concluir que os diamantes de pláceres quaternários associados ao Grupo Itararé provêm da erosão glacial de corpos kimberlíticos localizados naquele continente.

Fácies glaciogênicas trativas, fácies glaciais de sedimentos pré-enriquecidos e seus equivalentes ressedimentados, especialmente aqueles com maior maturidade litológica/mineralógica e textural, são rochas-alvo para diamante e um critério para prospecção e pesquisa.

Considerando ainda que ocorre ouro associado ao diamante na região do rio Tibagi, que as características particulares desses diamantes, associado ao fato de que os sedimentos glaciogênicos constituem importantes fontes secundárias de diamantes e de ouro, conclui-se que as rochas do Grupo Itararé constituem a área fonte secundária para as mineralizações quaternárias.

A ausência de fontes kimberlíticas ou lamproíticas, a assembleia similar de minerais pesados ultraestáveis do Grupo Itararé e dos pláceres diamantíferos, a presença neste grupo de fácies potencialmente concentradoras de diamantes, associadas a depósitos de glaciares oriundos do continente africano, indicam prováveis fontes primárias localizadas no sul da África.

Agradecimentos Ao PADCT pelos recursos financeiros para realização dos trabalhos de campo e laboratório, durante o projeto $\mathrm{n}^{\circ}$ 006591030300 PADCT/UFPR, a Capes pela concessão de bolsas de mestrado e de pesquisa do Curso de Pós-Graduação em Geologia da UFPR (processo $\mathrm{n}^{\circ}$ 530019/93). A dois revisores anónimos da RBG pelas sugestões.

\section{Referências}

McCallum, M. E. et al. 1991. Morphological, resorption and etch feature trends ofdiamonds from kimberlite populations within the Colorado-Wyoming State Linc District, USA. In: International Kimberlitc Confercncc 5, Araxá. Resumo Expandido, p.32-50.

Miall, A. D. 1983. Glaciomarine scdimentation. Gowganda Formation (Huronian) northern Ontario. Journal of Sedimentary Petrology, 53:477-491.

Oppenhcim, V. 1936. Sedimentos diamantiferos do Paraná. Rio de Janeiro: DNPM/DGM, (avulso) $14 \mathrm{p}$

Oppenhcim, V. 1943. Diamonds in the northeastcrn Bolivian Andes. Economic Geology, 3:658-661.

Perdoncini, L. C.; Soares, P. C. \& Bizzi, L. A. 1995. Diamonds associated with the Permo-Carboníferous glacial deposits in the Paraná Basin. In: International Kimberlite Conferenec 6, Novosibirsk. Extended Abstract..p.436-438.

Pcrdoncini L. C. \& Soares P. C., 1996. Arenito Barreiro na Bacia do Paraná: Fonte para o diamante do Tibagi? In: SBG, Congresso Brasileiro de Geologia, 39, Salvador, Anais, 3:146-148.

Pcrdoncini L. C. 1997. Diamantes do rio Tibagi, Paraná:fonte no Grupo Itararé?. Departamento de Geologia, Universidade Federal do Paraná, Curitiba, Dissertação de Mestrado, 164 p. Reis, L. T. \& Cunha Neto, A. F. 1982. Projclo diamantes - setor de rochas sedimentares. Curitiba: MINEROPAR, (relatório interno), $178 \mathrm{p}$

Rouffacr, E. J. H. F. 1988. On the origin of alluvial diamonds along the Atlantic Coast of South Africa and South West Africa. University of Lcuvcn, Belgium, Leuven,. Dr. Sc. Thesis, $125 \mathrm{p}$.

Rust, B. R. 1983. Coarse Alluvial deposits. In: WALKER, R. G. cd. Facies models 2 ed Toronto: Geoscience Canada, p. 9-21.

Smirnov, V. I. 1982. Geologia de vacimientos minerales. Moscou: MIR, 654

Soares, P. C.; Sá, G. \& Rabcllo, L. 1995. Mapa digital da Bacia do Paraná. (Rcl. UFPR/CNPq).

Sou/.a, M. M. 1993. Geologia dos diamantes do Estado de Roraima. In: SBG, Simpósio Brasileiro de Geologia do Diamante 1, Cuiabá, Anais, p.17-31.

Sutherland, D. G. 1982. The transport and sorting of diamond by fluvial and marine processes. Economic Geology, Lancaster, 77: 1613-1620.

Svisero, D. P. 1979. Inclusões minerais c génese do diamante do Rio Tibagi, Paraná. In: SBG, Simpósio Regional de Geologi,a, 2, Rio Claro, Arai, 2:169-180.

Svisero, D. P. 1994. Distribution and origin of diamonds in Brazil: an overview. In: International Symposium on The Physics and Chemistry of the Upper Mantle, 1, São Paulo. Invited Lectures, FAPESP, p. 257-287.

Tompkins, L. A. \& Gonzaga, G. M. 1989. Diamond in Brazil and a proposed model for the origin and distribution of diamonds in lhe Coromandel region, Minas Gerais. Brasil. Economic Geology, Lancaster, 84:591-602.

Wcska, R. K., et al. 1993. A estratigrafia, a evolução tectônica e o diamante do Grupo Bauru da região de Poxorco, MT, Brasil. In: Simpósio Brasileiro de Geologia do Diamante, 1, Cuiabá,. Anais, p. 208-228.

Wcska, R. K., 1996. A prospecção aluvionar de diamantes a partir do entendimento armadilhas "de traps", In: SBG, Congresso Brasileiro de Geologia, 39, Salvador, Anais, 3:189-191.

Wu, F.T. 1981. Minerais pesados das sequências arenosas Paleozóica e Mesozóica no centro-leste do Estado de São Paulo. Instituto de Geociências, Universidade de São Paulo, São Paulo, Dissertação de Mestrado, 79 p. 